in SSc patients with pulmonary fibrosis compared to other SSc patients $(\mathrm{p}<0.05)$. There was a significant correlation between sE-selectin level and DLCO $(r=-0.536, \mathrm{p}<0.01)$.

\begin{tabular}{llll}
\multicolumn{4}{l}{ Abstract THU0046 Table 1} \\
\hline RA & sE-selectin (ng/ml) & sL-selectin $(\mathbf{n g} / \mathrm{ml})$ & sP-selectin $(\mathrm{ng} / \mathrm{ml})$ \\
\hline SSc & $43.7 \pm 30.9^{\mathrm{a}}$ & $378 \pm 168^{\mathrm{b}, \mathrm{c}}$ & $383 \pm 198^{\mathrm{c}}$ \\
Healthy subjects & $44.9 \pm 22.3^{\mathrm{d}}$ & $552 \pm 224$ & $246 \pm 163$ \\
\hline
\end{tabular}

${ }^{a} p<0.05$ vs. healthy subjects; ${ }^{b} p<0.001$ vs. healthy subjects; ${ }^{c} p<0.01$ vs. $S_{S c} ;{ }^{d} p<0.01$ vs healthy subjects.

Conclusion These results suggest that the measurement of levels of serum soluble selectins may provide a useful additional marker for disease activity in RA patients and for pulmonary involvement, especially sE-selectin, in SSc patients.

\section{THU0047 MATRIXINS, CYTOKINES AND ADHESIVE IMMUNOGLOBULINS WITHIN OSTEOARTHRITIC JOINT}

J ??tovickova, H Hulejova, V Pesakova, M Adam.

\subsection{6/annrheumdis-2001.844}

Research Centrum, Institute of Rheumatology, Prague, Czech Republic

Background The most abundant joint disease is osteoarthritis. Recently it was classified as cartilagenous, synovial or osseous but the unique forms may be combined. The main feature of the disease is imbalance between synthetic and degradative processes within joint tissues. Executive part in degradative processes play matrix metalloproteinases, so called matrixins. In situ, they are induced by many stimuli, namely by cytokines and by interaction of different adhesive molecules with their ligands. Having been secreted into the extracellular space, they are activated by serine proteinases, or by other matrixins and inhibited by tissue inhibitors of matrix metalloproteinases, TIMPs.

Objectives In the sera of OA patients we found matrixins MMP9, MMP-2 and MMP-3 and TIMP-1 together with cytokines IL8 and TNF $\alpha$ and adhesive molecules ICAM-1 and VCAM-1. To distinguish between the forms of osteoarthritis, we search for these molecules in all joint tissues that is in cartilage, synovium, granulous tissue within subchondral bone, synovial fluid and blood serum. The joint tissues and fluids we obtained from surgery during total hip or knee replacement.

Methods The joint tissues were derived from 22 patients. The patients were 17 female and 6 male, 67,5 \pm 9,6 years old. The metalloproteinase spectrum in the body fluids and extracts of joint tissues were evaluated by zymography. The concentration of metalloproteinases and TIMP-1 were assessed by ELISA (Biotrak, Amersham Pharmacia Biotech), the concentration of adhesive immunoglobulins by Bender ELISA (MedSystems Diagnostics $\mathrm{GmbH}$ ), and the concentration of IL-8 and TNF $\alpha$ were determined on Immulite (DPC, USA).

Results We found that the most abundant matrixine within cartilage and synovium is either gelatinase A (MMP-2) or stromelysine-1 (MMP-3). On the other hand, within granulous tissue, blood sera and synovial fluid, the prevailing matrixine is gelatinase $\mathrm{B}$ or stromelysine- 1 . In cartilage, synovial fluid and blood serum TIMP-1 is abundant over sum of matrixins, whereas in synovium and granulous tissue the sum of matrixins is abundant over TIMP-1. There is about 2 to 10 times greater concentration of IL-8 in the cartilage than in other joint compartments.
We found significant correlation between levels of sICAM-1 and sVCAM-1; between TNF $\alpha$ and MMP-3, TIMP-1, sICAM-1, sVCAM-1, and IL-8; and between IL-8 and sICAM-1 in all solid joint tissues. In the synovial fluid and blood serum the correlation was less pronounced.

Conclusion There is a great degradative potential within all compartments of osteoarthritic joint due to presence of matrixins, namely that of stromelysin-1. Within cartilage and synovial fluid the proteolytic potential is equilibrated by TIMP-1 whereas within synovium and granulous tissue is not. Synovium and granulous tissue are highly probably the propellers of degradative process in osteoarthritis.

\section{REFERENCE}

1 Yoshihara $Y$, et al. Matrix metalloproteinases and tissue inhibitors of metalloproteinases in synovial fluids from patients with rheumatoid arthritis or osteoarthritis. Ann Rheum Dis. 2000;59:455-61

\section{THU0048 ADDITION OF THE RGD MOTIF IN THE FIBRE KNOB OF AN ADENOVIRAL VECTOR IMPROVED THE TRANSFECTION EFFICIENCY AND WHEN USED FOR OVEREXPRESSION OF IL-1RA RESULTED IN A MORE EFFECTIVE INHIBITION OF ARTHRITIS}

${ }^{1} \mathrm{FA}$ Van de Loo, ${ }^{1} \mathrm{AC}$ Bakker, 'LA Joosten, ${ }^{2} \mathrm{~V}$ Krasnykh, ${ }^{2} \mathrm{DT}$ Curiel, ${ }^{1} \mathrm{WB}$ Van den Berg. ${ }^{1}$ Rheumatology Research Laboratory; ${ }^{2}$ Gene Therapy Center, UMC St-Radboud, Nijmegen, The Netherlands

\subsection{6/annrheumdis-2001.845}

Background Adenoviral (Ad) vectors expressing anti-inflammatory cytokines are used for therapy in experimental arthritis. Cell recognition and entry is dependent on the initial recognition of the coxsackievirus and adenovirus receptor (CAR) on cells. Recently introducing an Arg-Gly-Asp (RGD) motif in the HI loop of the fibre knob modified the tropism of the virus. ${ }^{1}$ The RGD motif is capable of mediating a CAR-independent cell entry via interactions with the $\alpha v b 3$ and $\alpha v b 5$ integrins.

Objectives In this study we explored the transfection efficiency of the RGD modified viruses and investigated the effectiveness of intra-articular IL-1Ra overexpression in the collagen-induced arthritis (CIA) model mediated by the RGD modified vector compared to wildtype viruses.

Methods $10 \mathrm{e} 7 \mathrm{pfu}$ of the AdLuc, AdLucRGD, AdmIL-1Ra, or AdmIL-1RaRGD were intra-articularly injected in all experiments. The CIA model was used to compare the wild type and the RGD viruses on their ability to downregulate arthritis. DBA/ 1 mice were immunised with collagen type II, and boostered 22 days later. Four days after the booster the adenoviral vectors were injected into both knee joints of the mice. Clinical scores of the knee joints were on a scale of $0-3$.

Results Twenty-four hours after intra-articular injection of $10 \mathrm{e} 7$ pfu virus into normal knee joints, luciferase production in AdlucRGD injected joints was around 22 times higher than in Adluc injected joints. On day 26 of the CIA model, 10e7 pfu of AdLuc, AdLucRGD, AdmIL-1Ra, or AdmIL-1RaRGD were injected into the knee joints. Onset of the CIA was significantly inhibited in the AdmIL-1RaRGD group (clinical score in the knee joints at day 38 was $0.82 \pm 0.24$ ) compared to the other groups (clinical scores were $1.57 \pm 0.24$ for the AdmIL-1Ra group and $1.86 \pm 0.21$ for the AdLucRGD group).

Conclusion Transduction of the synovial lining cells in normal knee joints was up to 30 times more efficient when the RGD mediated pathway was used. CIA was significantly better 